\title{
Intraspecific divergence in sperm morphology of the green sea urchin, Strongylocentrotus droebachiensis: implications for selection in broadcast spawners
}

\author{
Mollie K Manier*1,2 and Stephen R Palumbi ${ }^{1}$
}

Address: ${ }^{1}$ Department of Biological Sciences, Hopkins Marine Station, Stanford University, Pacific Grove, CA, USA and ${ }^{2}$ Current address: Department of Biology, 110 Life Sciences Complex, Syracuse University, Syracuse, NY 13244, USA

Email: Mollie K Manier* - mkmanier@syr.edu; Stephen R Palumbi - spalumbi@stanford.edu

* Corresponding author

Published: 13 October 2008

BMC Evolutionary Biology 2008, 8:283 doi:10.1 186/147/-2/48-8-283
Received: 9 July 2008

Accepted: 13 October 2008

This article is available from: http://www.biomedcentral.com/I47I-2I48/8/283

(c) 2008 Manier and Palumbi; licensee BioMed Central Ltd.

This is an Open Access article distributed under the terms of the Creative Commons Attribution License (http://creativecommons.org/licenses/by/2.0), which permits unrestricted use, distribution, and reproduction in any medium, provided the original work is properly cited.

\begin{abstract}
Background: Sperm morphology can be highly variable among species, but less is known about patterns of population differentiation within species. Most studies of sperm morphometric variation are done in species with internal fertilization, where sexual selection can be mediated by complex mating behavior and the environment of the female reproductive tract. Far less is known about patterns of sperm evolution in broadcast spawners, where reproductive dynamics are largely carried out at the gametic level. We investigated variation in sperm morphology of a broadcast spawner, the green sea urchin (Strongylocentrotus droebachiensis), within and among spawnings of an individual, among individuals within a population, and among populations. We also examined population-level variation between two reproductive seasons for one population. We then compared among-population quantitative genetic divergence $\left(Q_{S T}\right)$ for sperm characters to divergence at neutral microsatellite markers $\left(F_{\mathrm{ST}}\right)$.
\end{abstract}

Results: All sperm traits except total length showed strong patterns of high diversity among populations, as did overall sperm morphology quantified using multivariate analysis. We also found significant differences in almost all traits among individuals in all populations. Head length, axoneme length, and total length had high within-male repeatability across multiple spawnings. Only sperm head width had significant within-population variation across two reproductive seasons. We found signatures of directional selection on head length and head width, with strong selection possibly acting on head length between the Pacific and West Atlantic populations. We also discuss the strengths and limitations of the $Q_{S T}-F_{S T}$ comparison.

Conclusion: Sperm morphology in S. droebachiensis is highly variable, both among populations and among individuals within populations, and has low variation within an individual across multiple spawnings. Selective pressures acting among populations may differ from those acting within, with directional selection implicated in driving divergence among populations and balancing selection as a possible mechanism for producing variability among males. Sexual selection in broadcast spawners may be mediated by different processes from those acting on internal fertilizers. Selective divergence in sperm head length among populations is associated with ecological differences among populations that may play a large role in mediating sexual selection in this broadcast spawner. 


\section{Background}

Spermatozoa are the most morphologically diverse cells, yet they all have the same basic function: to fertilize an egg. Variation in sperm shape among species can often be attributed to sexual selection mediated by sperm competition [1-8] (but see [9]), but variation within species has been more difficult to explain. Male-to-male variation in sperm morphology has been documented in many species spanning a wide range of mating systems [10,11]. Functional studies investigating the within-species association between sperm length and fertilization success have found an advantage of larger sperm [12-16], but sometimes the race goes to the short [17]. Most often, though, no evidence is found for an intraspecific association of sperm morphology and sperm competition [18-27]. Thus, it remains unknown if selection is acting on sperm morphology in a similar way within and between species, or if sperm are evolving under complex, possibly contextdependent selective regimes that vary among species and populations $[16,17,28]$.

Most studies of sperm variation focus on organisms with internal fertilization, where sperm act in the context of an environment controlled by the female reproductive tract $[10,16,17]$. In such cases, sperm competition is dependent on multiple matings by the female and may be influenced by efforts of males to displace sperm from prior matings or to guard females against subsequent matings [29]. There may also be indirect effects of males on female behavior [30].

Some external fertilizers can likewise have complex mating systems with mate choice, male-male competition, and alternative male mating strategies [7,21,26]. However, fertilization dynamics of broadcast spawning organisms may face different selective rules. Mating occurs when typically sessile or sedentary adults release their gametes into the environment, resulting in external fertilization, and has been best studied in marine systems. Some species, particularly invertebrates, have a limited behavioral repertoire as adults and exhibit little behavioral mate choice. In dioecious species, female multiple mating is controlled largely by the density of males in her vicinity, and competition between males is relegated to the level of the gamete. Sperm competition may be high when synchronous spawning occurs in dense aggregations $[31,32]$, but intensity of sperm competition (as a function of sperm density), and therefore sexual selection, may vary over small spatial and temporal scales with changes in population density. Furthermore, fertilization conditions may be additionally influenced by variation in factors including wave action [33,34], temperature [35-37], or egg size $[34,38]$, creating a selective mosaic in which no single sperm type is universally preferred. Sperm variation among species of broadcast spawners is well-described [39-42] and can be associated with egg size and developmental mode [40]. While little is known about evolutionary forces acting on sperm morphology within a broadcast spawning species, they are certainly more related to ecological environmental variation rather than to conditions within a female reproductive tract.

A basic question is whether sperm morphology of a broadcast spawner varies substantially among males, as has been found in both internal and other external fertilizers [10,11]. Additionally, does sperm morphology vary among populations, a pattern that precedes species-level divergence? We address these questions in the green sea urchin (Strongylocentrotus droebachiensis), by examining variation in five sperm morphometrics within and among Pacific, West Atlantic and East Atlantic populations. We also assess the stability of sperm parameters over time within an individual across multiple spawnings and within a population across two reproductive seasons.

In order to determine if selection is driving populationlevel divergence in sperm morphology, we compare quantitative genetic divergence in sperm traits $\left(Q_{\mathrm{ST}}\right)$ with a neutral expectation of differentiation under genetic drift, estimated by divergence at neutral microsatellite loci $\left(F_{\mathrm{ST}}\right.$ [43-46]). The comparison of $Q_{\mathrm{ST}}$ with $F_{\mathrm{ST}}$ is a useful tool for identifying local adaptive differentiation in fitnessrelated quantitative traits, because it allows us to test a hypothesis of selection against three predictions [44]. If sperm morphology is neutrally divergent among populations, we would expect to see comparable patterns of variation at both sperm morphometrics and neutral microsatellites $\left(Q_{\mathrm{ST}}=F_{\mathrm{ST}}\right)$. If sperm traits are under directional selection for different optima among populations, quantitative trait divergence should be higher than expected under neutrality $\left(Q_{\mathrm{ST}}>F_{\mathrm{ST}}\right)$. Finally, if sperm traits are evolving under homogenizing selection, population means should be more similar than expected under neutrality $\left(Q_{\mathrm{ST}}<F_{\mathrm{ST}}\right)$, though this conclusion is much more difficult to obtain with confidence. $Q_{\mathrm{ST}}-F_{\mathrm{ST}}$ analysis has been applied in a wide range of taxa to address diverse questions in evolutionary biology, e.g., [47-49].

Here, we show that sperm traits have diverged strongly among populations as well as among individuals within populations. At the same time, sperm morphology exhibits low variation within individual males across multiple spawnings. We detect directional selection on sperm traits for different population means, especially in sperm head length between the Pacific and West Atlantic populations. Patterns of pairwise divergence among populations suggests that ecological variables may be playing a large role in sperm evolution of this broadcast spawner. 


\section{Results and Discussion Variation within males}

We tested sperm from multiple spawnings of males held in culture in 2006 and 2007. Among 15 males measured every two weeks two to five times (average $=3$ ), head length, axoneme length and total length did not differ significantly among spawning events (Table 1; for brevity, only head length shown in Figure 1A). However, head width and midpiece area showed significant within-individual variation over time. Repeatability ranged from 0.2 to 0.77 , with the highest repeatabilities obtained for head length, axoneme length and total length (Table 2). These repeatabilities are estimates of the upper limit of broadsense heritability and were used in the calculation of $Q_{\mathrm{ST}}$ for each trait.

Within-male variability in sperm morphometry as measured by within-male CV did not differ for the three populations for any trait except head width $(\mathrm{F}=8.92$; $\mathrm{P}<$ $0.0001)$. CV of head length among males within a population showed a clinal pattern with lowest among-male variability in the Pacific and highest in the East Atlantic. In all other traits, the West Atlantic had the highest variability among males, with the lowest in Norway. Head width was an exception, with the lowest variability among males in the Pacific. In general, patterns of variability within and among individuals were comparable for all traits and all populations, but midpiece area in the East Atlantic was an order of magnitude more variable within males than among males. In fact, midpiece area in all populations was much more variable than the other traits, with $\mathrm{CV}^{\prime} \mathrm{s}$ within males of 47.8 in the Pacific, 62.1 in the West Atlantic and 31.7 in the East Atlantic. Among-male CV's for midpiece area were 33.1 in the Pacific, 42.5 in the West Atlantic, and 5.6 in the East Atlantic.

In our study, we found strong evidence that sperm morphology is controlled more by developmental factors during spermatogenesis than ambient environmental conditions. We examined repeatability for West Atlantic males that were removed from the field and placed into a common laboratory environment. All sea urchins were spawned upon arrival from the field, so the first spawning should reflect sperm morphology under the native ecological conditions of the population. Individuals were usually spawned repeatedly over a time period exceeding the expected 21-day duration of a spermatogenic cycle ([50]; i.e., every two weeks for up to eight weeks). The result of repeatable sperm morphology, despite a change in environmental conditions between the field and the lab, suggests that differences between males are intrinsic properties of those males and not dominated by environmental effects. Furthermore, consistency in sperm morphology between 2006 and 2007 samples, despite differences in laboratory conditions of temperature and light regime, lend additional evidence to this conclusion. Understanding how size in sperm cells is controlled between males, and how intra-individual variance is limited will require a closer look at the molecular mechanisms controlling spermatogenesis in this system.

Ejaculate and sperm traits in fish have been shown to adjust in response to change in social status and therefore risk of sperm competition [51]. In addition, male fowl exhibit phenotypic plasticity in ejaculate size [52-54] and sperm velocity [55] under varying risk of sperm competition and depending on female number, quality and mating history. It is possible that similar plasticity exists in sea urchins, perhaps in response to population density, but because the captive environment was held constant for the duration of the study, we were unable to assess any plasticity in sperm morphology relative to sperm competition risk (e.g., density).

\section{Variation among males}

We found highly significant variation among individuals within all three populations for all sperm traits (Table 1; head length shown in Figure 1B) with the exception of midpiece area in the East Atlantic population $\left(F_{5,130}=\right.$ $0.76, P=0.58)$. Significant correlations among males were also found between head length and width $(r=-0.379, P$ $=0.0006)$, head length and axoneme length $(r=-0.349, P$

Table I: Summary of results testing for differences between various groups.

\begin{tabular}{|c|c|c|c|c|c|c|c|c|c|c|c|c|c|c|}
\hline & \multicolumn{2}{|c|}{ Measure } & \multicolumn{2}{|c|}{ Year } & \multicolumn{2}{|c|}{ Spawn } & \multicolumn{2}{|c|}{ Pacific } & \multicolumn{2}{|c|}{ West Atlantic } & \multicolumn{2}{|c|}{ East Atlantic } & \multicolumn{2}{|c|}{ Pop } \\
\hline & $F$ & $P$ & $t$ & $P$ & $F$ & $P$ & $F$ & $P$ & $F$ & $P$ & $F$ & $P$ & $F$ & $P$ \\
\hline $\mathrm{HL}$ & 0.55 & 0.46 & 1.22 & 0.2287 & 2.32 & 0.09777 & 8.27 & $<0.0001$ & 11.23 & $<0.000$ I & 44.47 & $<0.0001$ & 36.48 & $<0.0001$ \\
\hline $\mathrm{HW}$ & 0.46 & 0.50 & 3.88 & 0.0005 & 7.31 & 0.00097 & 5.4 & $<0.0001$ & $25.76,9.13$ & $<0.0001,<0.0001$ & 15.82 & $<0.0001$ & 23.61 & $<0.0001$ \\
\hline $\mathrm{AL}$ & 0.04 & 0.84 & -0.56 & 0.5765 & 0.61 & 0.61723 & 8.86 & $<0.0001$ & 10.98 & $<0.000$ I & 4.51 & 0.0008 & 8.43 & 0.0005 \\
\hline TOTAL & 0.00 & 0.98 & -0.53 & 0.598 & 0.95 & 0.42989 & 6.79 & $<0.0001$ & 10.36 & $<0.0001$ & 4.4 & 0.001 & 2.9 & 0.0612 \\
\hline MA & 3.62 & 0.06 & 2.45 & 0.0194 & 4.84 & 0.008 & 13.23 & $<0.0001$ & 12.5 & $<0.0001$ & 0.76 & 0.5789 & 8.15 & $<0.0001$ \\
\hline
\end{tabular}

Results for trait differences between measurement events (Measure), 2006 and 2007 West Atlantic sperm traits (Year), among spawnings within an individual (Spawn), among individuals within populations (Pacific, West Atlantic, East Atlantic), and among populations (Pop). For HW, individual differences within West Atlantic reported for 2006 and 2007, respectively, and Pop reflects separate accounting for the West Atlantic population by year. Sperm traits are head length $(H L)$, head width $(H W)$, axoneme length $(A L)$, total length (TOTAL), midpiece area (MA). 
Table 2: Results of global $Q_{S T}$ analysis for sperm traits.

\begin{tabular}{lcccccc}
\hline & Repeatability & $Q_{S T}$ & $F$ & $P$ & $Q_{S T} / F_{S T}$ & $P_{X}^{2}$ \\
\hline HL & 0.77 & 0.57 & 36.48 & $<0.0001$ & 3.57 & 0.0283 \\
HW & 0.29 & 0.65 & 20.09 & $<0.0001$ & 4.10 & 0.0166 \\
AL & 0.58 & 0.27 & 8.43 & 0.0005 & 1.68 & 0.1865 \\
TOTAL & 0.56 & 0.09 & 2.90 & 0.0612 & 0.55 & 0.5755 \\
MA & 0.20 & 0.50 & 8.03 & 0.0007 & 3.14 & 0.0432 \\
Average & 0.48 & 0.41 & & & & \\
SE & 0.10 & 0.10 & & & &
\end{tabular}

Microsatellite-based $F_{S T}=0.159 . F$ and $P$ correspond to the ANOVA from which variance components were obtained for calculating $Q_{S T}$. $P_{X}{ }^{2}$ is the $p$-value associated with the chi-squared distribution, for the test statistic $\left(n_{\text {demes }}-I\right) Q_{\mathrm{ST}} / F_{\mathrm{ST}}$.

$=0.0016)$, axoneme length and total length $(r=0.954, P$ $<0.0001)$, and head width and midpiece area $(r=0.565$, $P<0.0001$; Table 1).

An evolutionary process separate from that acting among males may influence the developmental system that produces sperm within a male. Significant differences in sperm morphological variation among males coupled with high repeatability provide strong support for the hypothesis that males control sperm morphology around an individually based mean. Yet, there is some variation within a spawning, and the CVs of sperm size within a male are comparable to those among males within a population.

\section{Variation among populations}

Population means were different for all sperm traits except total length $\left(F_{2,76}=2.9, P=0.06\right)$, including head length, head width, axoneme length and midpiece area (Table 1). Sperm heads in the Pacific are long (mean head length $=6.95 \mu \mathrm{m}, \mathrm{SD}=0.29$ ) and narrow (mean head width $=1.60 \mu \mathrm{m}, \mathrm{SD}=0.07)$ but in the East Atlantic, they are short (mean head length $=5.74 \mu \mathrm{m}, \mathrm{SD}=0.44$ ) and wide (mean head width $=1.94 \mu \mathrm{m}, \mathrm{SD}=0.12$ ), with the West Atlantic having an intermediate head shape (mean head length $=6.22, \mathrm{SD}=0.36$; mean head width $=1.64$, $\mathrm{SD}=0.13$; Table 3). Axoneme length was longest in the Pacific and shortest in the East Atlantic and negatively correlated with head length (Table 1), resulting in an overall equality of total length in all three populations. Head length was the only trait with significantly different means for all populations, according to a Tukey test (Table 4). Head width was significantly different only in the East Atlantic population, and axoneme length increased from west to east, with the West Atlantic not significantly different from the Pacific or East Atlantic populations. Midpiece area was distinct only for the West Atlantic population (Table 4).
Multivariate canonical discriminant analysis found significant among-population variation for overall sperm morphology, with two canonical variables (Figure 2; Wilks' lambda $=10.68, P<0.0001)$. CAN1 accounted for $75.7 \%$ of the variation and had highest raw canonical coefficients for head length, axoneme length, and total length (Additional file 1). Pairwise Mahalanobis distances among the three populations showed Pacific sperm morphology to be most divergent from the East Atlantic, with the West Atlantic showing approximately equal divergence from both the Pacific and the East Atlantic (Additional file 2).

Population trait means did not differ in the West Atlantic between 2006 and 2007 for all traits except head width (Table 1), suggesting that the population means for most sperm traits are stable over at least two reproductive seasons. Further research is needed to determine longer-term persistence of measured population means for this and the other populations.

To date, investigations of variation in sperm morphology among populations are limited, but population-level variation has been found across a wide range of taxa. A study of two closely related Drosophila species found significant differences in sperm length among individuals and populations in both species [56]. A study in Drosophila subobscura found population differences in sperm head length but not total length [57], and [58] found significant variation among males in total length within and among four populations of a frog.

In S. droebachiensis, substantial sperm differences among populations could be derived from a number of causes. The Atlantic populations probably originated from an invasion from the Pacific 3.5 million years ago with the opening of the Bering Strait [59]. Since that time, the western Atlantic population has received substantial influx from the Pacific [60], while the eastern Atlantic population has remained largely separated [61]. This demographic history is reflected in its population genetics [62], with an $F_{\mathrm{ST}}$ between the Atlantic populations of 0.204 and between the western Atlantic and Pacific of 0.014. In contrast, the two Atlantic populations are more similar to each other in overall sperm morphology than they are to the Pacific (Table 4). In particular, $Q_{\mathrm{ST}}$ divergence between the Pacific and West Atlantic exceeds their pairwise $F_{\mathrm{ST}}$ by a factor of 47, more than an order of magnitude higher than for the other population comparisons and traits (Figure 3).

Ecological differences among populations do a better job than genetic relationships at explaining the pattern of variation in sperm head length. In the Pacific, S. droebachiensis is embedded in a complex community that includes 24 congeners, some of which may act as competitors for 


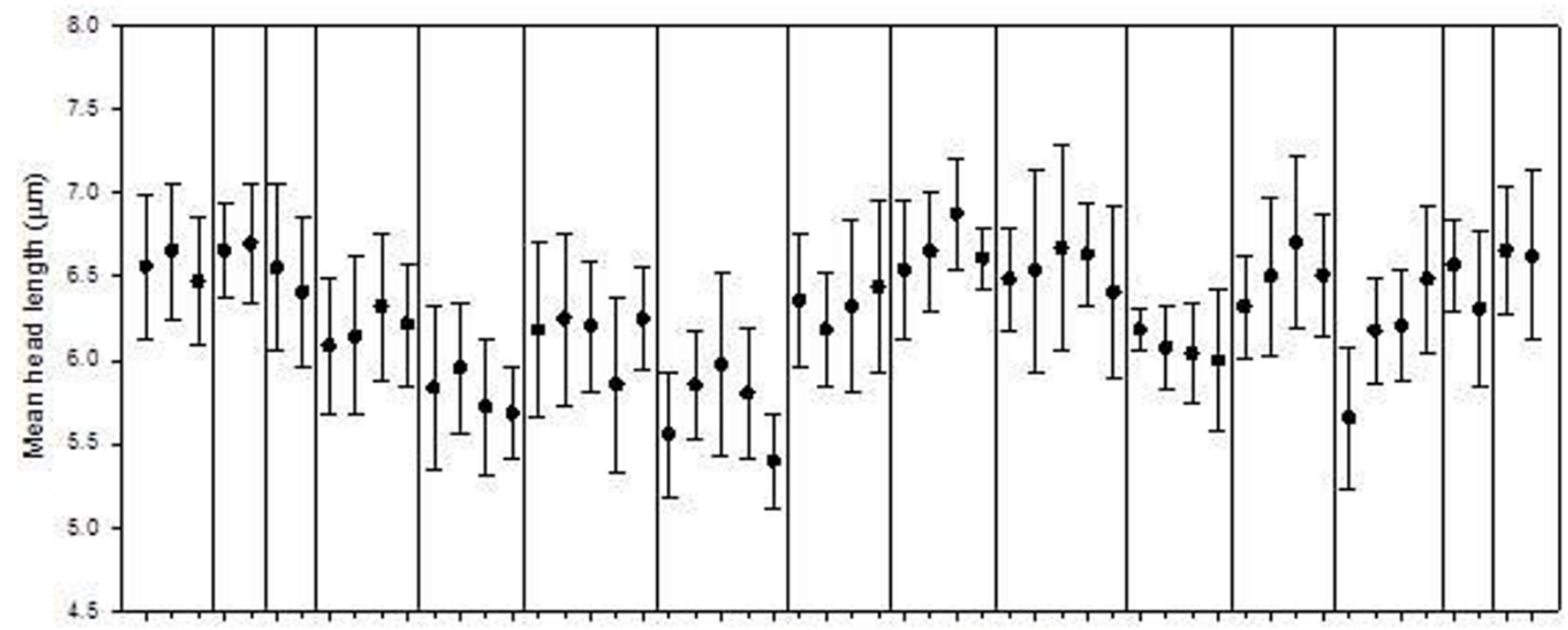

Spawning grouped by individusl

(B)

Pacific

West Atlantic

East

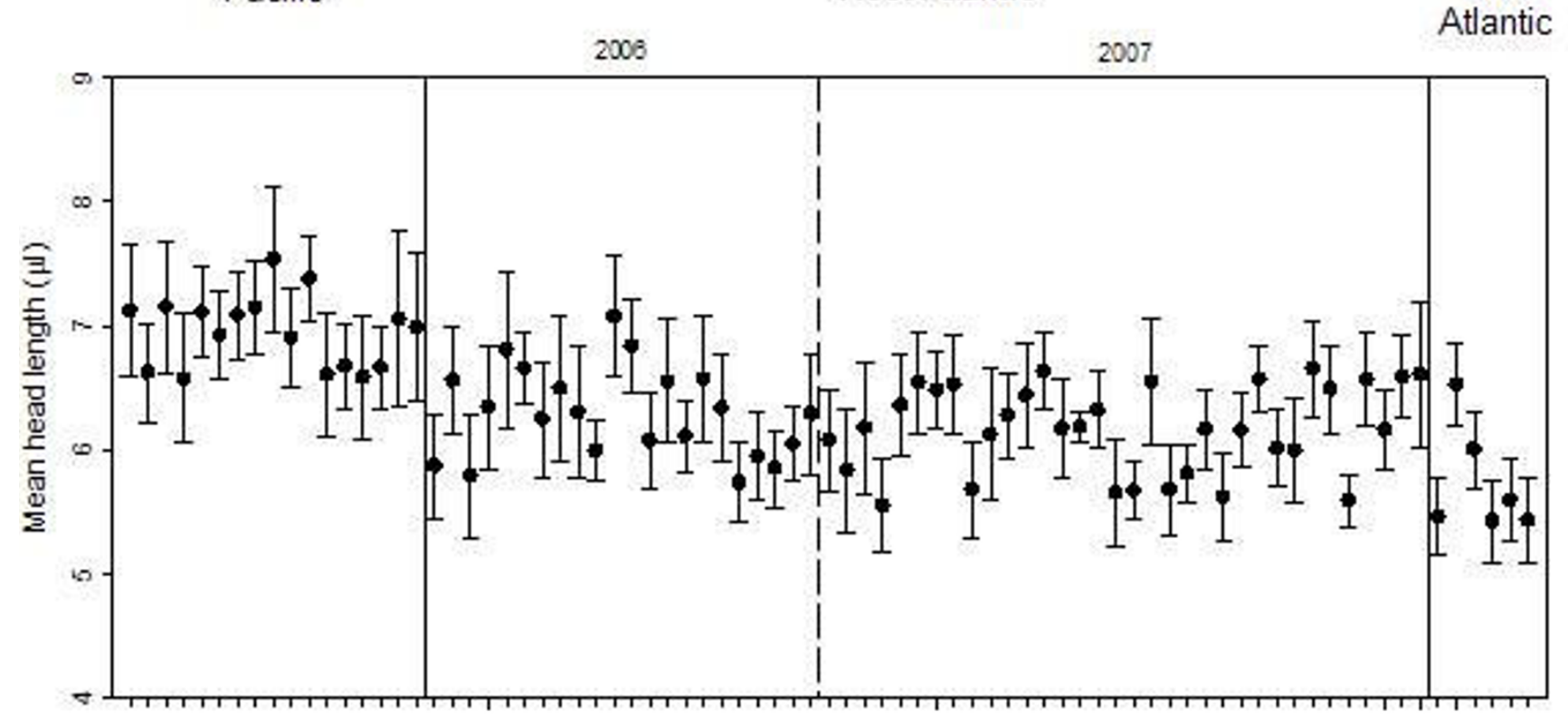

Figure I

Sperm head length variation. Mean individual sperm head length (error bars \pm I SD) (A) among spawnings within individuals (separated by vertical solid lines). (B) within and among populations (separated by vertical solid lines), and 2006 and 2007 samples from the West Atlantic (separated by vertical dashed line). 
Table 3: Population means and SD, average divergence among populations of sperm traits. Divergence expressed in units of average within-population phenotypic standard deviation (SD).

\begin{tabular}{lcccccccc}
\hline & \multicolumn{2}{c}{ Pacific } & \multicolumn{2}{c}{ West Atlantic } & \multicolumn{2}{c}{ East Atlantic } & \multirow{2}{*}{ Avg SD } & Divergence \\
& Mean & SD & Mean & SD & Mean & SD & Aven \\
\hline HL & 6.95 & 0.29 & 6.22 & 0.36 & 5.74 & 0.44 & 0.37 & 2.21 \\
HW & 1.6 & 0.07 & 1.64 & 0.13 & 1.94 & 0.12 & 0.10 & 2.16 \\
AL & 42.4 & 1.20 & 44.02 & 1.79 & 45.02 & 0.75 & 1.24 & 1.40 \\
TOTAL & 49.32 & 1.09 & 50.31 & 1.80 & 50.77 & 0.78 & 1.22 & 0.79 \\
MA & 1.67 & 1.18 & 2.12 & 1.17 & 1.75 & 1.03 & 1.13 & 0.27 \\
\hline
\end{tabular}

resources. In these Pacific habitats, $S$. droebachiensis is currently at lower population densities than the shallow water congeners, S. purpuratus and S. franciscanus [34], and has been characterized as a species that is sperm-limited in its spawning events [34,63]. In the Atlantic, on the other hand, $S$. droebachiensis can form dense stands of urchins that are capable of monopolizing the sea floor and stripping the habitat of macroalgae $[64,65]$. In such areas of high population density, sperm competition will be stronger than in most Pacific areas. The ecological similarity of the two Atlantic populations is more closely associated with the morphological similarity of sperm head length between these two populations relative to the Pacific. Increasing the sample size of the east Atlantic dataset and further study of historical population sizes may provide a clearer pattern of any association between sperm head morphology and population density among the study populations. In addition, experimental fertilization trials will be needed to test for any functional significance of these differences.

Evolutionary processes responsible for the observed sperm morphological variation among males may be illuminated by examining similar patterns in other male reproductive traits. In particular, the gamete recognition protein bindin shows strong differences between species as well as between some populations ([66-68] but also has high levels of polymorphism among individuals. Bindin has been shown to be evolving under balancing selection, mediated by sex-dependent, frequency-dependent,

Table 4: Results of Tukey test (d.f. 3, 76) for multiple comparisons of population means.

\begin{tabular}{lccc}
\hline & P & WA & EA \\
\hline HL & A & B & C \\
HW & A & A & B \\
AL & A & AB & B \\
TOTAL & A & A & A \\
MA & A & B & A \\
\hline
\end{tabular}

Significantly different groups $(P<0.0 \mathrm{I})$ designated with different letters $(A, B, C)$. For example, all three populations are different for $\mathrm{HL}$, but none are different for TOTAL. Trait abbreviations as in Table I. and density-dependent selection in the red sea urchin $(S$. franciscanus) $[69,70]$, and the context-dependent nature of bindin's fitness effects may explain both its rapid evolution and high allelic diversity [71]. If balancing selection is also acting on sperm morphology, we might see high morphological diversity within populations (as shown here). We would also expect fitness effects of sperm traits to be context dependent. These different contexts may be characterized by variation in population density (and therefore risk of sperm competition), egg morphology and/or turbulence due to wave action, but further experimental evidence is needed.

Alternatively, sperm morphological traits may be evolving neutrally among males within populations of $S$. droebachiensis. Determination that intraspecific variation is under selection will require further comparisons with other species that occur at higher abundances (e.g., S. purpuratus and S. franciscanus) and an understanding of the dynamics of sperm precedence in males with different sperm head sizes.

\section{Inferring selection by comparing $\mathbf{Q}_{S T}$ and $\mathbf{F}_{S T}$}

Heterozygosities and tests of Hardy-Weinberg equilibrium for the East Atlantic and Pacific populations are as reported in [62] for the Vestfjorden, Norway and San Juan Channel, Washington populations, respectively. The West Atlantic population had a heterozygote deficit at two loci (Loc76 and Loc63) and between 16 and 23 alleles per locus with an average of 18.75 . Global $F_{\mathrm{ST}}$ was 0.159 , with pairwise $F_{\mathrm{ST}}$ 's of 0.014 between the Pacific and West Atlantic, 0.318 between the Pacific and East Atlantic, and 0.203 between the two Atlantic populations.

Quantitative genetic divergence among populations exceeded microsatellite divergence for most sperm traits. Average $Q_{\mathrm{ST}}$ for the sperm traits was 0.41 , with a standard error of 0.10 , as compared with $F_{\mathrm{ST}}$ of 0.159 . ANOVAs of trait divergence from which variance components were obtained for calculating $Q_{\mathrm{ST}}$ were significant for all traits except total length. $Q_{\mathrm{ST}}$ 's for head length $\left(Q_{\mathrm{ST}}=0.57 ; P=\right.$ $0.028)$, head width $\left(Q_{\mathrm{ST}}=0.65 ; P=0.017\right)$, and midpiece area $\left(Q_{\mathrm{ST}}=0.50 ; P=0.043\right)$ were significantly higher than $F_{\mathrm{ST}}$, based on tail probabilities of $Q_{\mathrm{ST}}$ on a chi-squared $F_{\mathrm{ST}}$ 


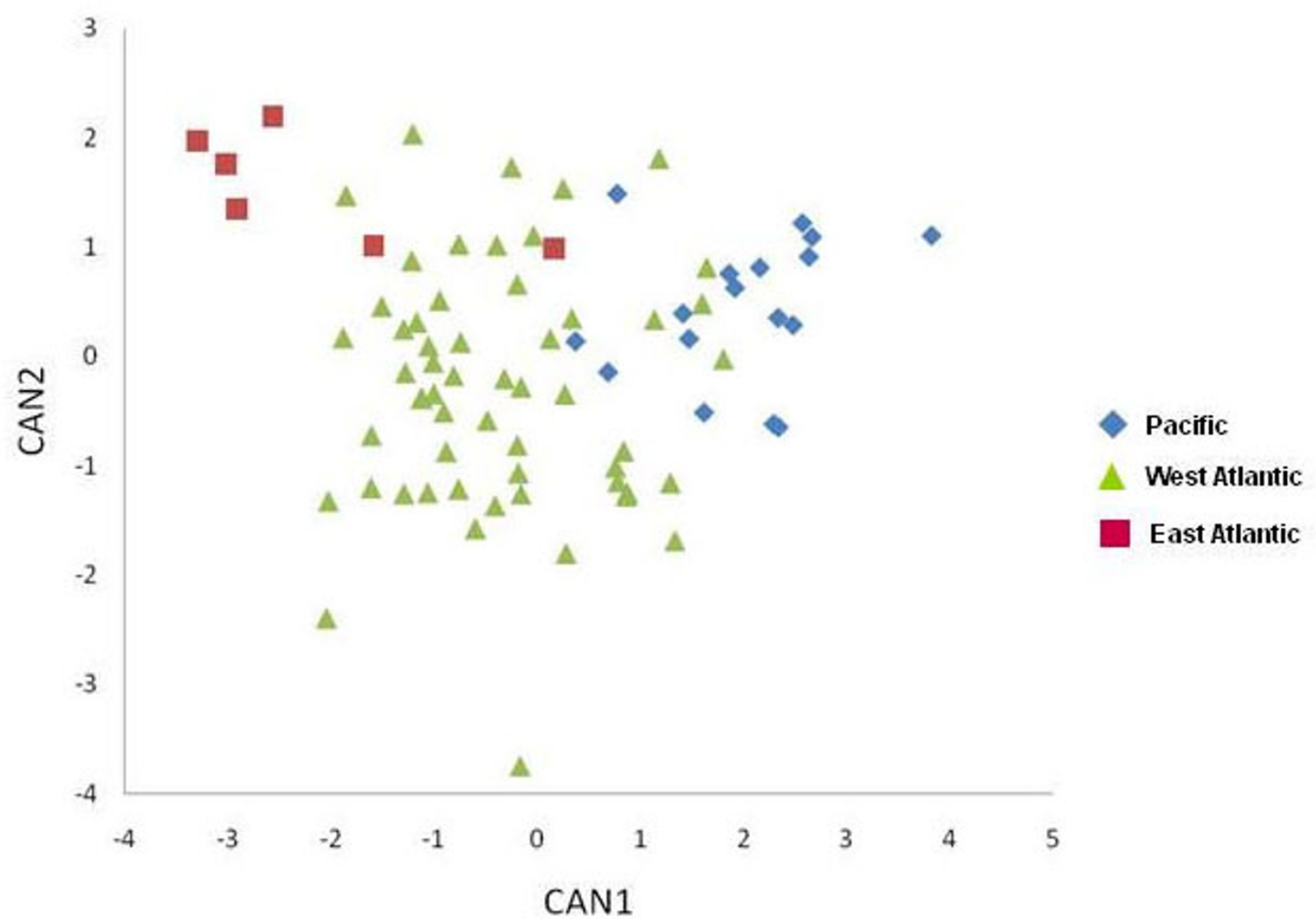

\section{Figure 2}

Overall morphological variation among populations. Scatterplot of CANI on CAN2 from multivariate canonical discriminant analysis. Blue diamonds are Pacific individuals, green triangles West Atlantic, and red squares East Atlantic.

distribution ([72]; Table 2), although these results are not significant after Bonferroni correction.

Calculation of population pairwise $Q_{\mathrm{ST}}$ and $F_{\mathrm{ST}}$ shows that marginal signatures of selection at the global level are driven entirely by highly significant quantitative trait divergence between the Pacific and West Atlantic. Sperm head length $\left(Q_{\mathrm{ST}} / F_{\mathrm{ST}}=42.76 ; P_{X}{ }^{2}=6.20 \times 10^{-11}\right)$, axoneme length $\left(Q_{\mathrm{ST}} / F_{\mathrm{ST}}=19.87 ; P_{X^{2}}=8.28 \times 10^{-6}\right)$ and midpiece area $\left(Q_{\mathrm{ST}} / F_{\mathrm{ST}}=33.62 ; P_{X}{ }^{2}=6.68 \times 10^{-9}\right)$, are most divergent, in comparison with a pairwise $F_{\mathrm{ST}}$ of 0.0136 (Figure $3)$.

We used repeatability of sperm traits as an estimate of the upper limit of broad-sense heritability in our calculations of $Q_{S T}$; the actual narrow-sense heritability for the sperm traits may be substantially lower. However, heritability of sperm morphometrics has been measured directly in a number of other species and has been found to be generally high. For example, heritability of sperm head length has been estimated to be 0.48 in zebra finches [73] and 0.72 in rabbits [74], comparable to our upper limit estimate of 0.77 .

Nevertheless, the use of repeatability in the calculation of $Q_{\mathrm{ST}}$ requires discussion of two key points. First, because repeatability is an upper limit on heritability, these $Q_{\mathrm{ST}}$ estimates represent their lower limit given the observed phenotypic population differentiation and are therefore not expected to further approach $F_{\mathrm{ST}}$. Our estimates of $Q_{\mathrm{ST}}$ are thus very conservative, because heritability appears in the denominator of the $Q_{\mathrm{ST}}$ calculation and therefore has an inverse relationship with $Q_{\mathrm{ST}}$ (Figure 4). Using repeatability as an upper limit on heritability means that our $Q_{\mathrm{ST}}$ estimates represent a lower bound. Over all possible values of $h^{2}, Q_{\mathrm{ST}}$ remains above $F_{\mathrm{ST}}$ for all sperm traits except 


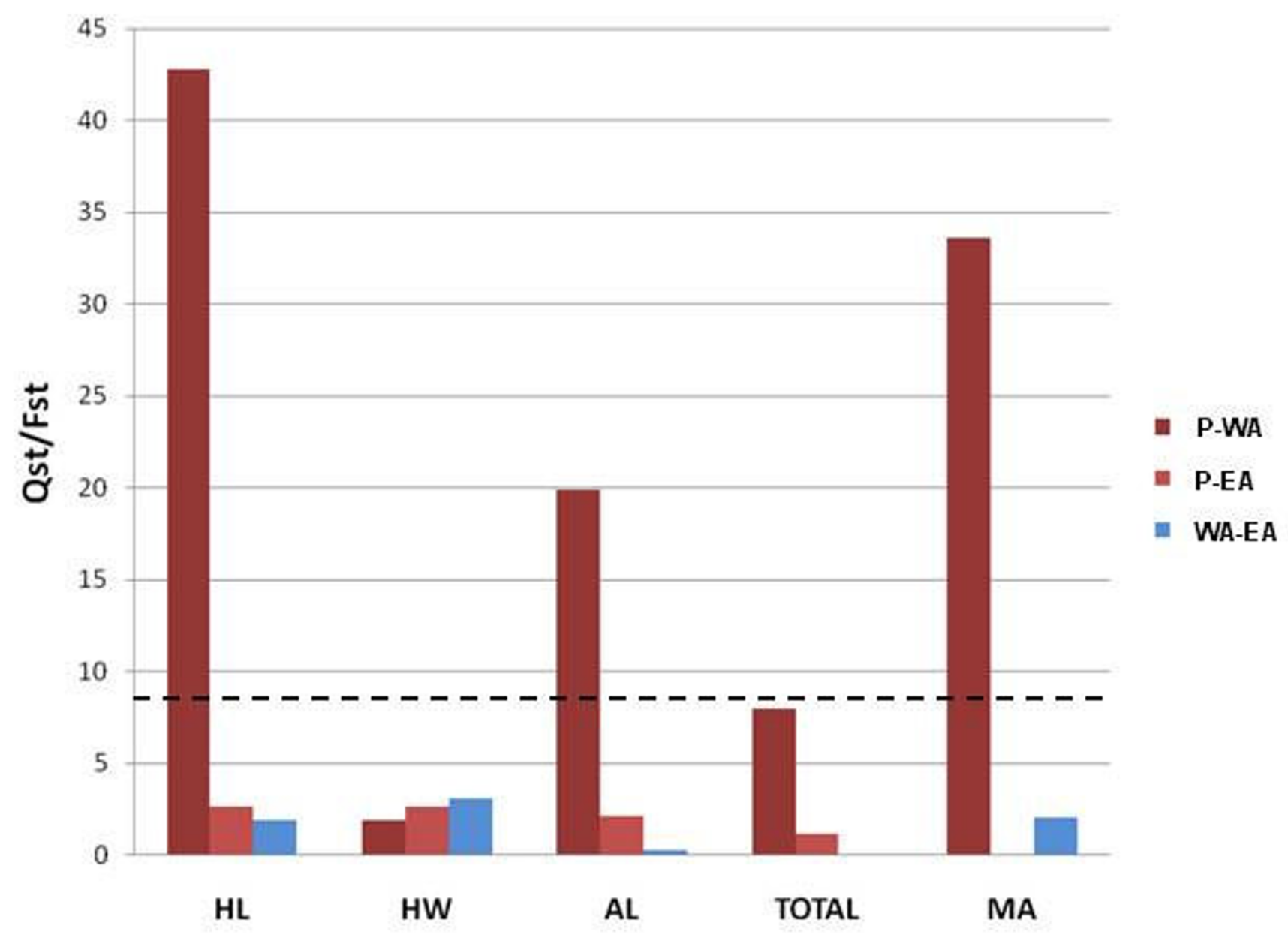

Figure 3

Pairwise $Q_{\mathrm{ST}} / F_{\mathrm{ST}}$ for all population pairs and all sperm traits. Atlantic-Pacific comparisons are in different shades of red. Pacific-West Atlantic (P-WA) in dark red, Pacific-East Atlantic (P-EA) comparison in pink, and West-East Atlantic (WAEA) comparison in blue. Head length (HL), head width (HW), axoneme length ( $A L)$, total length (TOTAL), midpiece area (MA). Dashed line represents the lower limit for statistically significant $Q_{\mathrm{ST}} / F_{\mathrm{ST}}(\alpha=0.05)$ after Bonferroni correction.

total length, though both axoneme length and midpiece area approach $F_{\mathrm{ST}}$ as $h^{2}$ reaches 1 (Figure 4 ).

Second, $F_{\mathrm{ST}}$ and $Q_{\mathrm{ST}}$ normally follow a chi-squared distribution ([72]), but $Q_{\mathrm{ST}}$ as estimated using repeatability, which estimates broad-sense heritability, no longer follows the same theoretical rules as a $Q_{\mathrm{ST}}$ estimated with an estimate of narrow-sense heritability. We can still calculate the tail probability of a point estimate of $Q_{\mathrm{ST}}$ on our chi-squared distribution of $F_{\mathrm{ST}}$, but we are unable to make any more rigorous statistical tests that take the distribution of $Q_{\mathrm{ST}}$ into account. This limitation also applies to the analysis of pairwise $Q_{\mathrm{ST}}$ and $F_{\mathrm{ST}}$.
As a more general precautionary note, our results, and those of many $Q_{\mathrm{ST}}-F_{\mathrm{ST}}$ comparisons, should be interpreted with a degree of caution. First, the chi-squared approximation of the $F_{\mathrm{ST}}$ distribution holds best when $F_{\mathrm{ST}}$ is less than 0.1 [72]. While our observed global $F_{\mathrm{ST}}$ of 0.159 may still reasonably follow a chi-squared distribution, the predictive capability of this model is diminished. Furthermore, an excess of $Q_{\mathrm{ST}}$ over $F_{\mathrm{ST}}$ may be obtained from selection acting not on the traits under study but on genetically correlated traits [72]. Finally, both $F_{\mathrm{ST}}$ and $Q_{\mathrm{ST}}$ are historical signatures of genetic divergence accumulated over time and are therefore unable to identify contemporary selection. Indeed, a result of $Q_{\mathrm{ST}}>F_{\mathrm{ST}}$ may result from selection 


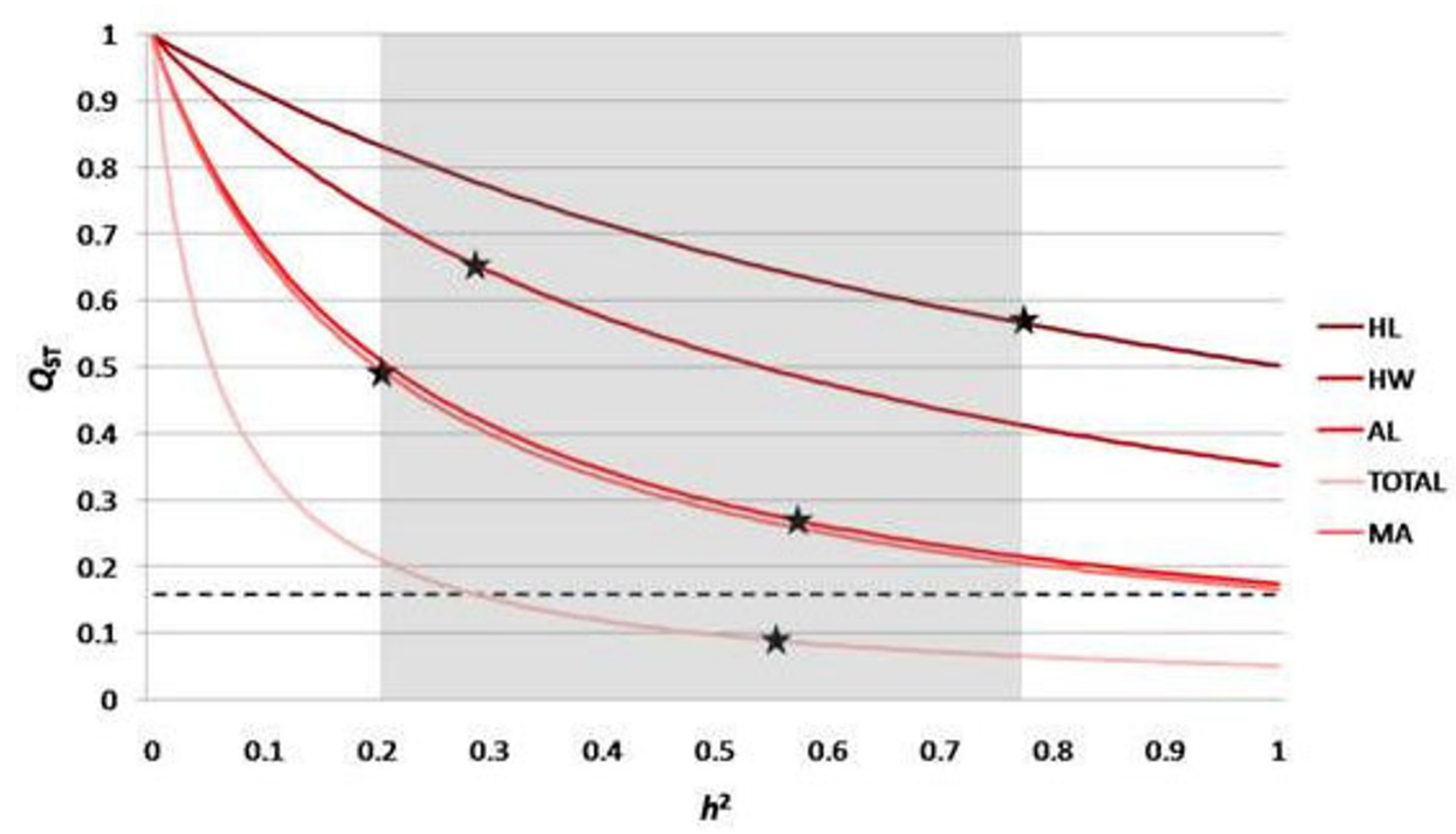

\section{Figure 4}

$\mathbf{Q}_{\mathrm{sT}}$ for sperm traits over all possible values of $\boldsymbol{h}^{\mathbf{2}}$ from $\mathbf{0}$ to $\mathbf{I}$. Stars indicate the values estimated in this study for sperm traits. Dashed line represents global $F_{\mathrm{ST}}=0.159$. Trait abbreviations are as in Figure 3 . Shaded gray area represents the range of repeatabilities estimated in this study.

or a response to past selection; these two possibilities cannot be differentiated by this analysis. Estimates of contemporary selection in this system may be especially useful, if evolution of sperm morphology is influenced by conditions controlling sperm competition that change on an ecological timescale. In short, the comparison of $Q_{\mathrm{ST}}$ and $F_{\mathrm{ST}}$ is a relatively blunt tool in evolutionary biology that can allow us to rule out genetic drift as a mechanism for quantitative trait differentiation and identify interesting traits for further study. The implications of directional selection derived here are preliminary at best and require more in-depth and rigorous analyses of selection for validation and detailed characterization.

\section{Head length and total length}

Of all sperm traits examined, head length was the only measurement to show stability over time within an individual as well as within a population, strong variation among males within all populations, and strong differentiation among all populations. Head length also had a strong signature of directional selection both at the global and population pairwise levels. Patterns of head elongation among sea urchin species are associated with the evo- lution of large eggs and direct development [40] (also see [42]), suggesting a mechanical role for sperm head shape in penetrating the egg's thick jelly coat. In other externally fertilizing taxa, phylogenetic comparisons show more ambiguity in an association between sperm morphology and egg morphology, with a positive relationship found in frogs [7], but not in fish $[4,6]$. In addition, sperm head shape, along with relative flagellum length, is positively correlated with risk of sperm competition across frog species [7]. The only evidence for a direct correlation between function and morphology within a species with flagellated sperm has been found in an internal fertilizer, the red deer [75]. Velocity is known to predict fertilization success in a wide variety of taxa $[21,76-78]$, including sea urchins [79], and head shape in broadcast spawners could play a role in swimming speed under different biomechanical conditions (e.g., turbulence, water velocity).

Total sperm length, on the other hand, showed no significant divergence or directional selection among populations. Other studies using phylogenetic contrasts and direct experiments also fail to find a significant relationship between indices of selection, such as sperm competi- 
tion, with sperm total length [18-23]. This lack of selective signal, may be due to opposing evolutionary forces acting on different subcomponents of sperm, such as head length and axomenal length that comprise total length. The negative correlation that we found between these two measurements (Table 1) underscores the importance of measuring subcomponents of sperm in addition to total length.

\section{Conclusion}

We found highly significant differences in sperm morphology among individuals within all populations for almost all traits, as well as strong population-level differentiation for head length, axoneme length, and midpiece area. At the same time, most traits showed low variation among multiple spawnings within a male. These results suggest that sperm morphology tends to be developmentally stable over time, while evolutionary forces are maintaining high levels of variation among individuals and populations of $S$. droebachiensis. Comparison of $Q_{\mathrm{ST}}$ with $F_{\mathrm{ST}}$ suggests that directional selection may be acting among populations for overall sperm morphology, especially between the Pacific and West Atlantic populations, in which sperm evolution has greatly outpaced neutral genetic divergence.

Directional selection for different means between populations of broadcast spawners could be driven by a wide variety of ecological differences, such as population density as a result of community structure. Individual males also differ in sperm size within populations, suggesting that selection on sperm traits is not only directional but may also involve balancing selection for traits that are most successful in different environments. Males from many species show this pattern in reproductive traits, suggesting that balancing selection, if acting, is not mating system-specific. It is also possible that variance between populations and species is under selection but that variance between males is drifting neutrally. The underlying genetic and developmental architecture that leads to variance between males in sperm morphology are largely unknown but represent a key area of research in elucidating the evolution of complex morphological phenotypes.

\section{Methods}

\section{Obtaining and preparing samples}

We examined sperm morphology in green sea urchins (Strongylocentrotus droebachiensis) from three populations, from the eastern Pacific (Friday Harbor, Washington, USA), West Atlantic (Woods Hole, Massachusetts, USA) and East Atlantic (Bødo, Norway). Individuals were obtained from the Pacific and West Atlantic from January to April 2006 and from the West Atlantic from February to April 2007. Sperm samples from the East Atlantic population were kindly provided by Nils Hagen in March 2006.
In 2006, adult S. droebachiensis were maintained at $14^{\circ} \mathrm{C}$ in outdoor seawater tanks under the local natural light regime at Hopkins Marine Station in Pacific Grove, California, USA and fed giant kelp (Macrocystis pyrifera) ad libitum. These individuals were reproductively active until late April. In 2007, a different cohort of adults was kept in an indoor seawater facility maintained at $8^{\circ} \mathrm{C}$ under a daily cycle of 13 hours of light and 11 hours of darkness. These individuals were also fed kelp ad libitum and were reproductively active through mid-June. Comparison of sample means between the different treatment conditions of 2006 and 2007 were done for the West Atlantic population using a t-test (see Data analysis section below).

Sea urchins were induced to spawn by injecting $0.55 \mathrm{M}$ $\mathrm{KCl}$. Most individuals were spawning on arrival after shipment, allowing a baseline measurement of sperm morphology before placement in common tanks. Dry sperm was collected off gonopores using a pipettor with a widebore tip, diluted 1:50 or 1:100 in filtered sea water (FSW), and fixed in a final concentration of $1 \%$ paraformaldehyde and 9.25\% FSW.

\section{Sperm fixation, microscopy and morphometrics}

Ten $\mu$ l of fixed sperm were pipetted on a slide, and a cover slip was applied and sealed with nail polish. Individual spermatozoa were visualized using differential interference light (DIC) microscopy with a Zeiss Axioplan DIC microscope at $250 \times$ to $1000 \times$ magnification. Digital micrographs were taken using an Olympus E330, E995 or E4500 digital camera. Measurements on images were obtained using ImageJ software (available at http:// rsb.info.nih.gov/ii/) and converted from units of pixels to microns based on a scale specific to the focal length of the camera and the ocular magnification. Scales were calculated using a stage micrometer (SPI Supplies, ser. no. CS2397).

We measured five sperm traits: head length, head width, axoneme length, total length, and midpiece area (Additional file 3). All spermatozoa chosen for measurement appeared normal with a visible endpiece to ensure presence of the entire axoneme. Total length did not include the endpiece. In 2006, we measured these traits for 15 males from the eastern Pacific, 22 males from the West Atlantic and six males from the East Atlantic (19-27 spermatozoa each). We also measured 33 males from the West Atlantic in 2007 (ten spermatozoa each) to assess annual variation in that population. All sperm measurements were repeatable across two measurement events (Table 1) at the $\alpha=0.05$ level after Bonferroni correction for multiple comparisons [80].

\section{Data analysis}

Normality of data by individuals and populations were evaluated visually using box plots and scatter plots gener- 
ated in SAS v. 9.1 (SAS Institute 2002), and only midpiece area data were log-transformed. All statistical analyses described below were performed in SAS, and Bonferroni correction was applied for each analysis. Repeatability of sperm measurements across two separate measurement events was determined for five males (ten spermatozoa each) from all three populations, using repeated measures ANOVA. We also spawned 15 males from the west Atlantic population (from both 2006 and 2007) every two weeks a total of two to five times and measured ten to 25 sperm from each spawning event to evaluate individual variation through time. These data were also analyzed using repeated measures ANOVA. We estimated correlations between pairwise individual trait means across the entire dataset using Pearson correlation coefficients. We also estimated coefficients of variation (CV) within and among males for all populations.

We examined the 2006 and 2007 spawning seasons in the west Atlantic population for differences in sperm morphology using a two-sample t-test and determined that only head width was significantly smaller in 2007 than in 2006 (Table 1). For this trait, subsequent analyses considered the 2006 and 2007 samples separately for the West Atlantic population. We used ANOVA to examine differences among individuals for each population separately as well as among populations, using individual means. Post-hoc multiple comparisons tests for differences of population means were performed using Tukey tests for all sperm traits. In order to account for population differentiation of multivariate sperm morphology, we performed a canonical discriminant analysis (PROC CANDISC; SAS v. 9.1), which asks if sperm from all populations are morphologically indistinguishable overall.

We tested the hypothesis that the amount of divergence in sperm traits among populations was significantly higher than we would expect for neutral variation, indicating directional selection for different trait means among populations. This test of selection was performed for each sperm trait by comparing quantitative genetic divergence or $Q_{\mathrm{ST}}$ with $F_{\mathrm{ST}}$ at neutral microsatellite markers. $Q_{\mathrm{ST}}$ was estimated from descriptive components of variance obtained by analysis of variance, computed using RANDOM in PROC GLM in SAS and Type III sums of squares accounting for unbalanced design. $Q_{\mathrm{ST}}$ was calculated as $Q_{\mathrm{ST}}=\frac{V_{G B}}{V_{G B}+2 V_{G W}}[44]$, where $V_{G B}$ is the among-population variance for quantitative traits, and $V_{G W}$ is the average within-population genetic variance. $V_{G W}$, in turn, was computed as the product of the trait heritability $\left(h^{2}\right)$ and the within-population component of variance $\left(V_{W}\right): V_{G W}$ $=h^{2} V_{W}$.

We derived our estimates of heritability for each sperm trait from our measurements of repeatability, calculated using morphometric data from multiple spawnings of the same male [81]. Repeatability was determined using variance components of among-spawnings ANOVA and represents the maximum value of the broad-sense heritability of a trait [82]. Heritability is inversely related to $Q_{\mathrm{ST}}$ due to its position in the denominator of the $Q_{\mathrm{ST}}$ equation. As a result, the estimates of $Q_{\mathrm{ST}}$ calculated using repeatability are very conservative and represent a lower limit on possible $Q_{S T}$ 's over the range of heritability from 0 to 1 , given the observed among-population trait divergence.

$F_{\mathrm{ST}}$ at four neutral microsatellite markers was estimated using AMOVA in Arlequin v. 2.000 [83] from published [62] and unpublished data (J. Addison) for the San Juan Islands, Washington, USA $(n=41)$; Isle of Shoals, New Hampshire, USA $(n=144)$; and Vestfjorden, Norway $(n=$ $79)$. All of these sites are geographically identical or proximate to those from which adults were obtained for the sperm variation data. While $F_{\mathrm{ST}}$ was not estimated from the same individuals from which sperm measurements were taken, both the sperm morphometric and microsatellite datasets were derived from the same geographic populations. The West Atlantic population had the largest distance between sampling localities of the two datasets, but previous research has shown that the West Atlantic region experiences high levels of gene flow [62]. Therefore, we do not expect these two localities (Isle of Shoals, New Hampshire and Woods Hole, Massachusetts) to be significantly genetically distinct. We did not obtain a standard error for $F_{\mathrm{ST}}$, because jackknifing cannot be done over only three populations. Mitochondrial DNA has also been used to estimate $F_{\mathrm{ST}}[84,85]$, but these genes represent a single locus that may not be evolving under neutrality [86] and so were not included in this analysis.

We tested the hypothesis that our estimates of $Q_{\mathrm{ST}}$ were significantly different from the neutral model represented by $F_{\mathrm{ST}}$. Because $F_{\mathrm{ST}}$ estimates can be highly variable among neutral loci, it is best to compare $Q_{\mathrm{ST}}$ not to a mean $F_{\mathrm{ST}}$ but to a distribution of possible $F_{\mathrm{ST}}$ 's [72]. The distributions of neutral $F_{\mathrm{ST}}$ and $Q_{\mathrm{ST}}$ have been shown to follow a chisquared distribution under a wide range of demographic scenarios [72]. As a result, we can compare the $Q_{\mathrm{ST}}$-to- $F_{\mathrm{ST}}$ ratio to a chi-squared distribution with $\left(n_{\text {demes }}-1\right)$ degrees of freedom, according to the statistic $\left(n_{\text {demes }}-1\right) Q_{\mathrm{ST}} / F_{\mathrm{ST}}$ [72], where $n_{\text {demes }}$ is the number of demes. The p-value associated with this statistic gives the probability that the observed $Q_{\mathrm{ST}}$ falls within the distribution of $F_{\mathrm{ST}}$. A significant $\mathrm{p}$-value for a sperm trait would indicate that it has a 
low probability of being selectively neutral and a high probability of evolving under directional selection.

To test for an effect of low sample size in the East Atlantic population, we performed a Bartlett's test for homogeneity of variances among all populations for each sperm trait. None of the sperm traits examined showed significant differences in variance among the populations, suggesting that although the East Atlantic sample size is small, there was no associated increase in variance. Most of the statistical tests performed in this study are based on ANOVA, which assumes equal variance among samples. Thus, we do not feel that the small sample size of the East Atlantic population has compromised our results in any way.

\section{Authors' contributions}

MM collected and analyzed data and drafted the manuscript. SP provided input on data analysis and the manuscript. Both authors read and approved the final manuscript.

\section{Additional material}

\section{Additional file 1}

Table of sperm trait correlations ( $r$ ) above diagonal and P-values below diagonal.

Click here for file

[http://www.biomedcentral.com/content/supplementary/1471-

2148-8-283-S1.doc]

\section{Additional file 2}

Table of raw canonical coefficients of sperm traits for both canonical variables from canonical discriminant analysis.

Click here for file

[http://www.biomedcentral.com/content/supplementary/14712148-8-283-S2.doc]

\section{Additional file 3}

Table of squared Mahalanobis distances from canonical discriminant analysis of overall sperm morphology between population pairs

Click here for file

[http://www.biomedcentral.com/content/supplementary/14712148-8-283-S3.doc]

\section{Additional file 4}

Green sea urchin sperm (A) components and (B) traits measured. Click here for file

[http://www.biomedcentral.com/content/supplementary/14712148-8-283-S4.doc]

\section{Acknowledgements}

We are grateful to Nils Hagen for providing sperm samples; Jason Addison for generously sharing unpublished data; David Duggins and the Marine Resources Center (Woods Hole, Mass., USA) for collecting urchins; Ana Quintana for sperm micrographs and animal care; Palumbi lab members and two anonymous reviewers for comments on the manuscript; and funding by PISCO, NSF grant OCE-07I4997 to SRP and NIH grant 5 F32 GM07348I to MKM. Funding bodies played no role in the data collection and analysis or the writing and submission of this manuscript.

\section{References}

I. Briskie JV, Montgomerie R: Sperm size and sperm competition in birds. Proceedings of the Royal Society B 1992, 247( I):89-95.

2. Gage MJG: Associations between body size, mating pattern, testis size and sperm lengths across butterflies. Proceedings of the Royal Society of London, Series B 1994, 258:247-254.

3. Gomendio M, Roldan ERS: Sperm competition influences sperm size in mammals. Proceedings of the Royal Society of London, Series $B$ 1991, 243:181-185.

4. Stockley P, Gage MJG, Parker GA, Moller AP: Sperm competition in fishes: the evolution of testis size and ejaculate characteristics. American Naturalist 1997, I49(5):933-954.

5. Morrow EH, Gage MJG: The evolution of sperm length in moths. Proceedings of the Royal Society of London, Series B 2000, 267:307-3।3.

6. Balshine S, Leach BJ, Neat F, Werner NY, Montgomerie R: Sperm size of African cichlids in relation to sperm competition. Behavioral Ecology 200I, I 2(6):726-73I.

7. Byrne PG, Simmons LW, Roberts JD: Sperm competition and the evolution of gamete morphology in frogs. Proceedings of the Royal Society of London, Series B 2003, 270:2079-2086.

8. Immler S, Moore HDM, Breed WG, Birkhead TR: By hook or by crook? Morphometry, competition and cooperation in rodent sperm. PLoS One 2007, I(I):el70.

9. Gage MJG, Freckleton RP: Relative testis size and sperm morphometry across mammals: no evidence for an association between sperm competition and sperm length. Proceedings of the Royal Society B 2003, 270:625-632.

10. Kleven O, Laskemoen T, Fossøy F, Robertson RJ, Lifjeld JT: Intraspecific variation in sperm length is negatively related to sperm competition in passerine birds. Evolution 2007 in press.

II. Morrow EH, Gage MJG: Consistent significant variation between individual males in spermatozoal morphometry. Journal of Zoology 200I, 254:|47-I53.

12. LaMunyon CW, Ward S: Larger sperm outcompete smaller sperm in the nematode Caenorhabditis elegans. Proceedings of the Royal Society B 1998, 265:1997-2002.

13. Fitzpatrick JL, Desjardins JK, Milligan N, Montgomerie R, Balshine S: Reproductive-tactic-specific variation in sperm swimming speeds in a shell-brooding cichlid. Biology of Reproduction 2007, 77:280-284

14. LaMunyon CW, Ward S: Evolution of sperm size in nematodes: sperm competition favours larger sperm. Proceedings of the Royal Society B 1999, 266:263-267.

15. Radwan J: Intraspecific variation in sperm competition success in the bulb mite: a role for sperm size. Proceedings of the Royal Society of London, Series B 1996, 263:855-859.

16. Miller GT, Pitnick S: Sperm-female coevolution in Drosophila. Science 2002, 298: |23|-I233.

17. García-González F, Simmons LW: Shorter sperm confer higher competitive fertilization success. Evolution 2007, 6 I (4):8| 6-824.

18. Pitnick S, Miller GT, Reagan J, Holland B: Males' evolutionary responses to experimental removal of sexual selection. Proceedings of the Royal Society B 200I, 268: I07I-I080.

19. Hosken DJ, Ward PI: Experimental evidence for testis size evolution via sperm competition. Ecology Letters 200I, 4(I): I0-I3.

20. Hosken DJ, Garner TWJ, Ward PI: Sexual conflict selects for male and female reproductive characters. Current Biology $200 \mathrm{I}$, I I:489-493.

21. Gage MJG, Macfarlane CP, Yeates S, Ward RG, Searle JB, Parker GA: Spermatozoal traits and sperm competition in Atlantic salmon: relative sperm velocity is the primary determinant of fertilization success. Current Biology 2004, 14:44-47.

22. Simmons LW, Wernham J, Garcia-Gonzalez F, Kamien D: Variation in paternity in the field cricket Teleogryllus oceanicus: no detectable influence of sperm numbers or sperm length. Behavioral Ecology 2003, I(4):539-545.

23. Morrow EH, Gage MJG: Sperm competition experiments between lines of crickets producing different sperm lengths. 
Proceedings of the Royal Society of London, Series B 200I, 268:228I-2286

24. Gage MJG, Stockley P, Parker GA: Effects of alternative male mating strategies on characteristics of sperm production in the Atlantic salmon (Salmo salar): theoretical and empirical investigations. Philosophical Transactions of the Royal Society of London B 1995, 350(| 334):39|-399.

25. Vladiæ TV, Afzelius BA, Bronnikov GE: Sperm quality as reflected through morphology in salmon alternative life histories. Biology of Reproduction 2002, 66:98-105.

26. Leach B, Montgomerie R: Sperm characteristics associated with different male reproductive tactics in bluegills (Lepomis macrochirus). Behavioral Ecology and Sociobiology 2000, 49(I):3I-37.

27. Tomkins JL, Simmons LW: Sperm competition games played by dimorphic male beetles: fertilization gains with equal mating access. Proceedings of the Royal Society B 2000, 267: 1547-1553.

28. Anthes N, Schulenburg H, Michiels NK: Evolutionary links between reproductive morphology, ecology and mating behavior in opisthobranch gastropods. Evolution 2008, 62(4):900-916.

29. Simmons LW, Siva-Jothy MT: Sperm competition in insects: mechanisms and the potential for selection. In Sperm competition and sexual selection Edited by: Birkhead TR, Møller AP. San Diego: Academic Press; 1998.

30. Chapman T: Seminal fluid-mediated fitness traits in Drosophila. Heredity 200I, 87:5II-52I.

31. Yund PO, McCartney MA: Male reproductive success in sessile invertebrates: competition for fertilizations. Ecology 1994 75(8):2|5|-2|67.

32. Levitan DR: Density-dependent sexual selection in external fertilizers: variances in male and female fertilization success along the continuum from sperm limitation to sexual conflict in the sea urchin Strongylocentrotus franciscanus. American Naturalist 2004, 164(3):298-309.

33. Denny MW, Shibata MF: Consequences of surf-zone turbulence for settlement and external fertilization. American Naturalist 1989, I34(6):859-889.

34. Levitan DR: Density-dependent selection on gamete traits in three congeneric sea urchins. Ecology 2002, 83(2):464-479.

35. Greenwood PJ, Bennett T: Some effects of temperature-salinity combinations on the early development of the sea urchin Parechinus angulosus (Leske). Fertilization. Journal of Experimental Marine Biology and Ecology I98I, 5 I: I | 9-I31.

36. Mita M, Hino A, Yasumasu I: Effect of temperature on interaction between eggs and spermatozoa of sea urchin. Biological Bulletin 1984, 166:68-77.

37. Sewell MA, Young CM: Temperature limits to fertilization and early development in the tropical sea urchin Echinometra lucunter. Journal of Experimental Marine Biology and Ecology 1999, 236:29I-305.

38. Levitan DR: Effects of gamete traits on fertilization in the sea and the evolution of sexual dimorphism. Nature 1996, 382: 153-155.

39. Chia F-S, Atwood D, Crawford B: Comparative morphology of echinoderm sperm and possible phylogenetic implications. American Zoologist 1975, 15:553-565.

40. Raff RA, Herlands L, Morris VB, Healy J: Evolutionary modification of echinoid sperm correlates with developmental mode. Development, Growth and Differentiation 1990, 32(3):283-291.

41. Steiner SCC: La ultraesctructura de espermatozoides y su valor en la sistemática de Scleractinia (Cnidaria: Anthozoa). Revista de Biologia Tropical 1998, 46(suppl 5): |27-135.

42. Landry C, Geyer LB, Arakaki Y, Uehara T, Palumbi SR: Recent speciation in the Indo-West Pacific: rapid evolution of gamete recognition and sperm morphology in cryptic species of sea urchin. Proceedings of the Royal Society of London, Series B 2003, 270:1839-1847.

43. Lande R: Neutral theory of quantitative genetic variance in an island model with local extinction and colonization. Evolution 1992, 46(2):38I-389.

44. Spitze K: Population structure in Daphnia obtusa: quantitative genetic allozymic variation. Genetics 1993, 135:367-374.

45. Merilä J, Crnokrak P: Comparison of genetic differentiation at marker loci and quantitative traits. Journal of Evolutionary Biology 200I, 14:892-903.
46. McKay JK, Latta RG: Adaptive population divergence: markers, QTL and traits. Trends in Ecology and Evolution 2002, I7(6):285-29|.

47. Koch AM, Kuhn G, Fontanillas P, Fumagalli L, Goudet J, Sanders IR: High genetic variability and low local diversity in a population of arbuscular mycorrhizal fungi. Proceedings of the National Academy of Science 2004, I 0 I (8):2369-2374.

48. Goldringer I, Prouin C, Rousset M, Galic N, Bonnin I: Rapid differentiation of experimental populations of wheat for heading time in response to local climatic conditions. Annals of Botany 2006, 98:805-817.

49. Manier MK, Seyler CM, Arnold SJ: Adaptive divergence within and between ecotypes of the terrestrial garter snake, Thamnophis elegans, assessed with $F_{\mathrm{ST}}-\mathrm{Q}_{\mathrm{ST}}$ comparisons. Journal of Evolutionary Biology 2007, 20:1705-1719.

50. Himmelman $\mathrm{JH}$ : Reproductive cycle of the green sea urchin, Strongylocentrotus droebachiensis. Canadian Journal of Zoology 1978, 56:1828-1836.

51. Rudolfsen G, Figenschou L, Folstad I, Tveiten H, Figenschou M: Rapid adjustments of sperm characteristics in relation to social status. Proceedings of the Royal Society B 2006, 273:325-332.

52. Pizzari T, Cornwallis CK, Lovlie H, Jakobsson S, Birkhead TR: Sophisticated sperm allocation in male fowl. Nature 2003, 426:70-73.

53. Cornwallis CK, Birkhead TR: Changes in sperm quality and numbers in response to experimental manipulation of male social status and female attractiveness. The American Naturalist 2007, 170:758-770.

54. Cornwallis CK, Birkhead TR: Social status and availability of females determine patterns of sperm allocation in the fowl. Evolution 2006, 60: |486-1493.

55. Cornwallis CK, Birkhead TR: Experimental evidence that female ornamentation increases the acquisition of sperm and signals fecundity. Proceedings of the Royal Society B 2007, 274:583-590.

56. Joly D, Korol A, Nevo E: Sperm size evolution in Drosophila: inter- and intraspecific analysis. Genetica 2004, 1 20:233-244.

57. Snook RR: Absence of latitudinal clines in sperm characters in North American populations of Drosophila subobscura (Diptera: Drosophilidae). Pan-Pacific Entomologist 200I, 77(4):26I-27I.

58. Hettyey A, Roberts JD: Sperm traits of the quacking frog, Crinia georgiana: intra- and interpopulation variation in a species with a high risk of sperm competition. Behavioral Ecology and Sociobiology 2006, 59:389-396.

59. Durham JW, MacNeil FS: Cenzoic migrations of marine invertebrates through the Bering Strait region. In The Bering land bridge Edited by: Hopkins DM. Stanford, Calif.: Stanford University Press; 1967:326-349.

60. Palumbi SR, Wilson AC: Mitochondrial DNA diversity in the sea urchins Strongylocentrotus purpuratus and $S$. droebachiensis. Evolution 1990, 44(2):403-4I5.

6I. Biermann $\mathrm{CH}$, Kessing BD, Palumbi SR: Phylogeny and development of marine model species: strongylocentrotid sea urchins. Evolution and Development 2003, 5(4):360-37I.

62. Addison JA, Hart MW: Analysis of population genetic structure of the green sea urchin (Strongylocentrotus droebachiensis) using microsatellites. Marine Biology 2004, I 44:143-25I.

63. Levitan DR: The importance of sperm limitation to the evolution of egg size in marine invertebrates. American Naturalist 1993, $141(4): 517-536$

64. Hagen NT: Destructive grazing of kelp beds by sea urchins in Vestfjorden, northern Norway. Sarsia 1983, 68(3): 177-190.

65. Mann KH: Destruction of kelp-beds by sea-urchins: a cyclical phenomenon or irreversible degradation? Helgoland Marine Research 1977, 30(I-4):455-467.

66. Metz EC, Palumbi SR: Positive selection and sequence rearrangements generate extensive polymorphism in the gamete recognition protein bindin. Molecular Biology and Evolution 1996, 13(2):397-406.

67. Biermann $\mathrm{CH}$ : The molecular evolution of sperm bindin in six species of sea urchins (Echinoida: Strongylocentrotidae. Molecular Biology and Evolution 1998, I5( I2):|761-177|.

68. Geyer LB, Palumbi SR: Conspecific sperm precedence in two species of tropical sea urchins. Evolution 2005, 59(I):97-105.

69. Palumbi SR: All males are not created equal: fertility differences depend on gamete recognition polymorphisms in sea 
urchins. Proceedings of the National Academy of Science 1999, 96(22): $12632-12637$.

70. Levitan DR, Ferrell DL: Selection on gamete recognition proteins depends on sex, density, and genotype frequency. Science 2006, 3 1 2:267-269.

7I. Palumbi SR: Evolution of reproductive proteins. Heredity in press.

72. Whitlock MC: Evolutionary inference from $\mathbf{Q}_{\mathbf{S T}}$. Molecular Ecology 2008, I7(8): 1885-1896.

73. Birkhead TR, Pellatt EJ, Brekke P, Yeates R, Castillo-Juarez H: Genetic effects on sperm design in the zebra finch. Nature 2005, 434:383-387.

74. Napier RA: Fertility in male rabbit. 3. Estimation of spermatozoan quality by mixed insemination, and inheritance of spermatozoan characters. Journal of Reproduction and Fertility | 961, 2(3):273-289.

75. Malo AF, Gomendio M, Garde J, Lang-Lenton B, Soler AJ, Roldan ERS: Sperm design and sperm function. Biology Letters 2006, 2:246-249.

76. Malo AF, Garde J], García AJ, Gomendio M, Roldan ERS: Male fertility in natural populations of red deer is determined by sperm velocity and the proportion of normal spermatozoa. Biological Reproduction 2005, 72:822-829.

77. Birkhead TR, Martinez JG, Burke T, Froman DP: Sperm mobility determines the outcome of sperm competition in the domestic fowl. Proceedings: Biological Sciences 1999, 266(I 430): : 759-1764.

78. Froman DP, Feltmann AJ, Rhoades ML, Kirby JD: Sperm mobility: a primary determinant of fertility in the domestic fowl (Gallus domesticus). Biological Reproduction 1999, 61:400-405.

79. Levitan DR: Sperm velocity and longevity trade off each other and influence fertilization in the sea urchin Lytechinus variegatus. Proceedings of the Royal Society of London, Series B 2000, 267:531-534.

80. Rice WR: Analyzing tables of statistical tests. Evolution 1989, 43(I):223-225.

81. Lessells CM, Boag PT: Unrepeatable repeatabilities: a common mistake. The Auk 1987, 104:116-121.

82. Falconer DS, Mackay TFC: Introduction to quantitative genetics. Essex, England: Addison Wesley Longman Limited; 1996.

83. Schneider S, Roessli D, Excoffier L: Arlequin ver 2.000: a software for population genetics data analysis. Genetics and Biometry Laboratory, University of Geneva, Switzerland; 2000.

84. Addison JA, Hart MW: Colonization, dispersal, and hybridization influence phylogeography of North Atlantic sea urchins (Strongylocentrotus droebachiensis). Evolution 2005, 59(3):532-543.

85. Harper FM, Addison JA, Hart MW: Introgression versus immigration in hybridizing high-dispersal echinoderms. Evolution 2007, 6 I (I0):2410-24I8.

86. Rand DM: The units of selection on mitochondrial DNA. Annual Review of Ecology and Systematics 200I, 32:415-448.
Publish with Biomed Central and every scientist can read your work free of charge

"BioMed Central will be the most significant development for disseminating the results of biomedical research in our lifetime. "

Sir Paul Nurse, Cancer Research UK

Your research papers will be:

- available free of charge to the entire biomedical community

- peer reviewed and published immediately upon acceptance

- cited in PubMed and archived on PubMed Central

- yours - you keep the copyright
BioMedcentral 